\title{
MARKETING FUTURECAST LAB - PROSPECTING TRENDS FOR A BETTER FUTURE
}

\author{
Pedro Dionísio, ISCTE- University Institute of Lisbon, Portugal \\ Carmo Leal, Marketing FutureCast Lab, Portugal
}

\begin{abstract}
Marketing FutureCast Lab is a research and analysis lab targeting on international marketing trends. It was created in 2008 as a part of ISCTE - University Institute of Lisbon and has, as financing members, about 20 large national and multinational companies (TAP - Portuguese Airlines, Portugal Telecom, Unilever, Nestlé, Santander, Heineken Group...).

So far, the lab analyzed over 140 new trends, creating digests (short reports), developing market studies with innovative methodologies and supporting innovation processes inside partner companies.

The logics underlying our approach is that sustainability (either economic, social, environmental or cultural) will brand not only the companies' organizational structure but also each of the substantiations of new buying and consumption patterns inside the new normal we live in, where nothing is the way it was in the past.

New worries characterize this age of brand scrutiny. Social responsibility - companies' or individuals' - reflects in the market, in the choice of brands and selling points, in leaner processes to decide acquisition, in the transparency of digital media where companies show the consumers their inner reality.
\end{abstract}

References available upon request. 